\section{Agencia Acreditadora en Ciencias de la Salud}

A new Accreditation Agency for Health Sciences in Chile

La Comisión Nacional de Acreditación acordó autorizar a la Agencia Acreditadora en Ciencias de la Salud, AACS, para operar en los niveles de carreras profesionales y programas de pregrado en el área de la Salud. Esta autorización se extenderá por un plazo de siete años, a contar del 27 de enero de 2010, quedando sujeta a las condiciones de operación y la supervisión definidas por la Ley $\mathrm{N}^{\circ} 20.129$ y la Resolución Exenta $\mathrm{N}^{\circ} 165-3$.

Este acuerdo derivó de la preocupación de la Asociación Chilena de Facultades de Medicina
(ASOFAMECH) por la necesidad de evaluar la calidad de los programas de educación superior y, específicamente, de carreras en Ciencias Médicas. La experiencia acumulada por parte de académicos de las Facultades de Medicina y Ciencias Médicas en procesos de acreditación de programas y de las respectivas carreras profesionales, como en la evaluación del cumplimiento de los programas en Especialidades Médicas, llevó a la nominación de un grupo de académicos responsables de dirigir y desarrollar esta Agencia. Su Directorio lo preside el Dr. Gonzalo Grebe Barros, actuando como Secretario el Dr. Luis Barrueto Céspedes. La página Web www.aacs.cl proporcionará información para convenir contratos de acreditación entre las Facultades y la Agencia. 